\title{
Bingineering Jour'tial
}

Article

\section{Antibacterial Effects of Copper \\ Microparticles/Copper Nanoparticles/Copper(II) \\ Oxide Nanoparticles and Copper \\ Microparticles/Copper Nanoparticles/Copper(I) \\ Oxide Nanoparticles from Ultrasono-Electrochemical with Hydrothermal Assisted Synthesis Method}

\author{
Pachara Chalayon $^{\mathrm{a}}$ and Chanchana Tangwongsan ${ }^{\mathrm{b}, *}$ \\ Department of Electrical Engineering, Faculty of engineering, Chulalongkorn University, Bangkok 10330, \\ Thailand \\ E-mail : apachara.c171@gmail.com, b.*Chanchana.T@chula.ac.th
}

\begin{abstract}
Copper is a versatile metal with various properties, including antibacterial effects. There are many methods to produce nano-enhanced copper. In this study, we explore the ultrasono-electrochemical with hydrothermal assisted method to produce copper/copper oxides nanoparticles by using ultrasono-electrochemical process to produce copper micro/nano particles, ultrasonication process to produce copper oxide nanoparticles and hydrothermal process to produce cuprous oxide nanoparticles. Antibacterial properties of the produced particles were tested by conventional bacterial identification test and conventional total viable count test using 4 standard bacteria: Escherichia coli, Salmonella enteritidis, Staphylococcus epidermidis and Staphylococcus aureus. The results show that ultrasonoelectrochemical method can produce high purity copper micro and nano particles with zero oxidation with the average size of 575 and $118 \mathrm{~nm}$, ultrasonication process can produce copper oxide nanoparticles on copper microparticle and nanoparticle surfaces with the average size of $56 \mathrm{~nm}$, and hydrothermal process can produce cuprous oxide nanoparticles on copper microparticle and nanoparticle surfaces with the average size of $50 \mathrm{~nm}$. All particles with concentration of $0.5 \mathrm{mmol} / \mathrm{ml}$ are highly effective as antibacterial agents against Staphylococcus epidermidis. Copper oxide nanoparticles are effective against Salmonella enteritidis, Staphylococcus epidermidis and Staphylococcus aureus, while cuprous oxide nanoparticles are highly effective against all 4 species of bacteria, at over $99.17 \%$.
\end{abstract}

Keywords: Copper/copper oxides nanoparticles, antibacterial effects, ultrasonoelectrochemical method, ultrasonication method, hydrothermal method.

ENGINEERING JOURNAL Volume 25 Issue 6

Received 30 December 2020

Accepted 29 May 2021

Published 30 June 2021

Online at https://engj.org/

DOI:10.4186/ej.2021.25.6.55 


\section{Introduction}

Copper $(\mathrm{Cu})$ is a versatile material due to their various characteristics, including high conductivity, recyclability, and reactivity [1]. Copper is commonly used as electrical conductors, structure supporters, molds, water purifiers, and fertilizers [2-5]. Moreover, copper oxides, including copper(II) oxide $(\mathrm{CuO})$ and copper(I) oxide $\left(\mathrm{Cu}_{2} \mathrm{O}\right)$ are applied as semiconductors, antibacterial agents and chemical catalyzers [6].

Due to the development of nanotechnology, properties of copper and copper oxides in nanomaterial forms are continuously investigated. Copper nanoparticles (CuNPs) are described as particles with the size of $100 \mathrm{~nm}$ or less [7-9]. The CuNPs retain their electrical conductivity, but enhance the recyclability and chemical reactivity properties. At ambient conditions, CuNPs agglomerate but still retain all their nano-enhanced properties. Enhanced properties of copper oxides nanoparticles (CuONPs and $\mathrm{Cu}_{2} \mathrm{ONPs}$ ) are accelerated chemical reactions and antibacterial properties.

The antibacterial effects and applications of copper and copper compounds have been extensively investigated over the past decade. It has been found that copper and copper compounds are oligodynamic. A very small amount of them is capable of causing harmful effects to bacterial cells, known as 'contact killing', initiated by the release of copper ions from the copper surface. Membrane degradation and toxicity of copper are the two main mechanisms that cause damage or even death to the bacterial cells.

Membrane degradation is considered the initial effect of copper and copper oxides on the bacterial cells. Pure copper and copper oxides are capable of releasing ions to the environment. The positively charged copper ions can readily bind to the negatively charged molecules on the bacterial outer membrane. This disrupts the membrane functions and causes membrane degradation of both gram negative and gram positive bacteria.

Copper is an essential trace element for most living organisms, a small amount of copper ion is required for many metabolic activities of the bacterial cells. Many bacteria species use some mechanisms to transport extracellular copper ions into the cell. In normal condition, low level of copper ions can be maintained through $\mathrm{Cu}$ homeostasis mechanisms. However, at high level, copper ions can cause harmful effects to the bacterial cells.

There are several pathways for copper ions to enter the bacterial cells: the ions can bind with membrane transporters and being transported into the cell via some ion transport mechanisms or nano-sized copper ions can be imported via an outer membrane porin $[10,11]$. Membrane damage also provide a way for copper ions to enter the cell.

Once copper ions are in the cell, $\mathrm{CuO}$ produces reactive oxygen species or ROS, e.g., hydroxyl ions and superoxides, through Fenton-like reaction. ROS play a significant role in the homeostasis of the cells. In normal condition, the cells maintain ROS at low and stationary levels. However, at high level, ROS impair lipids, proteins, and nucleic acids, causing genetic materials degradation, cell circulation interruption and cell death $[11,12]$.

According to Fenton-like reaction, $\mathrm{Cu}(\mathrm{II})$ ions can be reduced to $\mathrm{Cu}(\mathrm{I})$ ions by hydroxyl ions and superoxides from cell components. The $\mathrm{Cu}(\mathrm{I})$ ions damage the metabolize enzyme by binding to the intracellular proteins, e.g., to the disulfide group of respiratory enzymes of cell membrane, leading to cell respiratory arrest and genetic materials degradation $[10,13,14]$.

The antibacterial properties of copper microparticles (CuMPs), copper nanoparticles (CuNPs), copper(II) oxide microparticles (CuOMPs) and copper(II) oxide nanoparticles (CuONPs) are similar to those of silver nanoparticles (AgNPs), but copper is more abundant and less expensive. There are many methods to synthesize copper and copper(II) oxide particles. Chemical reaction methods are the most studied as there are various factors (e.g., the temperature or the $\mathrm{pH}$ of the solution) to control the shape and the size of the particles [7, 8]. Most chemical reaction methods use at least one type of copper compound $\left(\mathrm{CuSO}_{4}, \mathrm{CuCl}_{2}\right.$ or $\left.\mathrm{Cu}\left(\mathrm{NO}_{3}\right)_{2}\right)$ combine with a reducing agent (ascorbic acid, oleic acid or $\mathrm{NaBH}_{4}$ ) and a stabilizing agent (starch, PVP, tree resins, or chitosan) or a buffer $\left(\mathrm{H}_{3} \mathrm{BO}_{3}\right.$ or $\left.\mathrm{C}_{4} \mathrm{H}_{4} \mathrm{KNaO}_{6}\right)[8,9,15-21]$. The size of the obtained copper particles ranges from $37 \mathrm{~nm}$ to 150 $\mathrm{nm}$. However, these methods always use toxic precursors or produce toxic wastes such as hydrochloric acid or sulfuric acid [9, 19, 21].

There are alternative methods for the synthesis of copper nanoparticles including wire explosion technique, photochemical method and ultrasono-chemical method. The wire explosion technique uses high energy pulse electrical discharge to explode copper wires. Although this technique uses no chemical reaction, it requires high voltage electricity and complicated synthesis equipment $[22,23]$. The photochemical method uses YAG laser on copper pieces dipping in a solvent (a mixture of water, ethanol and/or acetone). This method can produce high purity CuNPs [24-26]. However, a high energy light source and complicated equipment are required. The ultrasonochemical method applies the ultrasonication to assist chemical reactions in the solution of a copper salt and a reducing agent. This accelerates the chemical reactions, hence increases the production of CuNPs. This technique requires low-cost materials and simple experimental equipment, but the CuONPs are also produced from the soluble oxygen in the solution which lowers the purity of the obtained CuNPs $[27,28]$. However this CuONPs can be used to produced $\mathrm{Cu}_{2} \mathrm{ONPs}$ using the hydrothermal process $[29,30]$.

In this study, we investigate the antibacterial properties of the copper micro/nano particles and the copper oxides nanoparticles we synthesized using ultrasono-electrochemical method. The CuONPs in this study were produced by the ultrasonication process and the $\mathrm{Cu}_{2} \mathrm{ONPs}$ in this study were produced by the hydrothermal process. The advantage of these methods is that no toxic substances are used or produced. The properties of the copper and the copper oxides particles 
were determined using scanning electron microscopy (SEM), and energy dispersive x-ray spectrometry (EDS). The antibacterial properties were tested by conventional bacterial identification test and conventional bacterial viable count test using 4 ATCC standard bacteria: Escherichia coli, Salmonella enteritidis, Staphylococcus epidermidis and Staphylococcus aureus.

\section{Materials and Methods}

\subsection{Synthesis of CuMPs and CuMPs/CuNPs}

The electrochemical system for synthesizing CuMPs and CuMPs/CuNPs is composed of two electrodes partly submerged into the electrolyte. The electrolyte was prepared using a mixture of $10 \mathrm{mmol}$ of ascorbic acid, 2 $\mathrm{mg}$ of gum arabic and $200 \mathrm{ml}$ of deionized water (type II DI water). The solution was thoroughly stirred for 5 minutes and then put in a $250 \mathrm{ml}$ airtight beaker and maintained under ambient conditions for 1 hour. All the chemical reagents in this experiment are analytical grade without further purification. A copper rod (as the anode) and a tungsten rod (as the cathode) were used as the electrodes in this electrochemical system.

The synthesis of CuMPs was performed by applying a DC voltage of $0.75 \mathrm{~V}$ to the electrodes for 6 hours under ambient conditions. For CuMPs/CuNPs, the synthesis was performed under ambient conditions by applying a DC voltage of $0.75 \mathrm{~V}$ to the electrodes for two hours and 20 minutes during which ultrasonication (35W and $42 \mathrm{kHz}$ ) was also applied for 30 minutes, rested for 5 minutes and was repeated 4 times during the synthesis.

\section{2. $\mathrm{CuMPs} / \mathrm{CuNPs} / \mathrm{CuONPs}$ and $\mathrm{CuMPs} / \mathrm{CuNPs}$ $/ \mathrm{Cu}_{2} \mathrm{ONPs}$}

To synthesize CuMPs/CuNPs/CuONPs, the suspended CuMPs/CuNPs were separated from the electrolyte by sedimentation and $50 \mathrm{ml}$ of DI water was added into a $250 \mathrm{ml}$ beaker. The beaker of CuMPs/CuNPs were ultrasonicated for 1 hours 45 minutes until the color of the solution changed from pink to dark brown as shown in Fig. 1(c). To synthesize CuMPs/CuNPs/ $\mathrm{Cu}_{2} \mathrm{ONPs}$, the suspended CuMPs/CuNPs/CuONPs were heated at $100^{\circ} \mathrm{C}$ for two hours until the color of the solution changed from dark brown to yellow (CuMPs/CuNPs/Cur ONPs), as shown in Fig. 1(d).

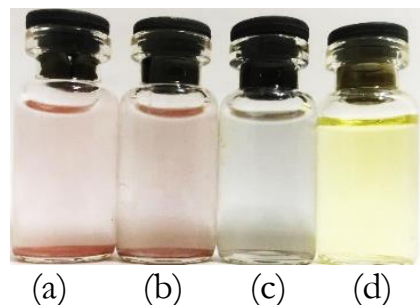

Fig. 1. From the left to right (a) CuMPs (b) $\mathrm{CuMPs} / \mathrm{CuNPs}$ (c) CuMPs/CuNPs/CuONPs and (d) CuMPs/CuNPs/ $\mathrm{Cu}_{2} \mathrm{ONPs}$.

\subsection{Antibacterial Test}

Antibacterial properties of $0.5 \mathrm{mmol}$ CuMPs, 0.5 mmol CuMPs/CuNPs, $0.5 \mathrm{mmol}$ CuMPs/CuNPs/ $\mathrm{CuONPs}$ and $0.5 \mathrm{mmol} \mathrm{CuMPs} / \mathrm{CuNPs} / \mathrm{Cu}_{2} \mathrm{ONPs}$ were tested using conventional bacterial identification test and conventional total viable count test [31] using 4 standard bacteria (McFarland Standard No. 0.5 of $1.5 \times 10^{8}$ colonies forming unit per $\mathrm{ml}(\mathrm{CFU} / \mathrm{mL})$ for each standard bacterium). Escherichia coli (E. coli, ATCC 22922), Salmonella enteritidis (S. enteritidis, ATCC 24213) Staphylococcus epidermidis (S. epidermidis, ATCC 12228), and Staphylococcus aureus (S. aureus, ATCC 25293) were used as two gram negative and two gram positive bacteria representatives, respectively.

In this research, related equipment was sterilized before testing in order to prevent any contamination. The broth was prepared using a mixture of $1 \mathrm{~g}$ of peptone water, $1 \mathrm{~g}$ of sodium chloride $(\mathrm{NaCl})$ and 11 of deionized water. The agar was prepared using a mixture of $17.54 \mathrm{~g}$ of tryptone glucose yeast agar (OXOID ${ }^{\mathrm{TM}}$ ) and 11 of deionized water.

\section{Conventional bacterial identification test}

The bacterial solutions were prepare using the mixture of $1 \mathrm{ml}$ of standard bacteria, $0.5 \mathrm{mmol}$ of antibacterial agent (in $1 \mathrm{ml}$ solution) and $1 \mathrm{ml}$ of deionized water. The $1 \mathrm{ml}$ of bacterial solutions were mixed into the 9-ml broth.

This specimen was then poured into a prepared agar petri-dish for bacterial culture. The sample was incubated at $37^{\circ} \mathrm{C}$ for $24 \mathrm{hrs}$. After incubation, the specimen was observed for the growth of the bacterial colony. The purpose of this test is to screen the potential bactericidal activity of the agent before continuing the test for quantitative result in the next procedure.

\section{Conventional total viable count test}

For the conventional total viable count test, the control sample was prepared by mixing 1-ml of each specimen with 9-ml broth. The samples were prepared at different concentrations by the ten-fold serial dilution. After dilution, the $0.1 \mathrm{ml}$ of each specimen were cultured onto the agar surface. The samples were incubated at $37^{\circ} \mathrm{C}$ for 24 hrs. After the incubation, the samples with the bacterial colonies ranged from 25-250 colonies were set as the final dilution. The ten-fold serial dilution is presented in Fig. 2.

The number of bacterial colonies were counted and determined as the total viable cells following Eq. (1).

$$
\mathrm{v}=\mathrm{n} \times 10^{(1+\mathrm{dt})}
$$

where

$\mathrm{v}=$ the total viable cells

$\mathrm{n}=$ the number of colonies

$\mathrm{dt}=$ dilution time $(\mathrm{s})$ 


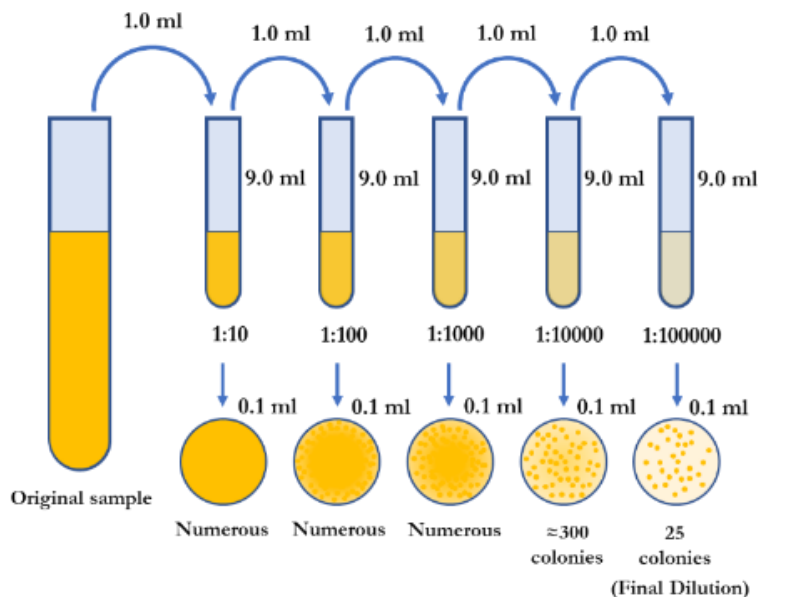

Fig. 2. The ten-fold serial dilution for conventional total viable count.

The value of the total viable cells is used to determine the percent reduction of bacteria following Eq. (2)

$$
\% \text { red }=\frac{\mathrm{v}}{1.5 \times 10^{8}} \times 100 \%
$$

where

$$
\begin{aligned}
\% \text { red } & =\text { the percent reduction of bacteria } \\
\mathrm{v} & =\text { the total viable cells }
\end{aligned}
$$

\subsection{Scanning Electron Microscopy (SEM) and Energy Dispersive Spectrometry (EDS)}

The obtained copper and copper oxides particles were analyzed using SEM/EDS system (Scanning Electron Microscopes SU3900, Hitachi ${ }^{\text {TM }}$ ). The samples were prepared by spreading the obtained particles on the surface of pure graphite substrates. SEM with the magnification of $\times 10,000$ to $\times 50,000$ using the applied voltage of $5-20 \mathrm{keV}$ was used to analyze the shape and the size of the obtained copper particles. EDS was used to analyze the elemental composition of the surface of the sample.

\section{Result and Discussion}

\subsection{Characteristic of CuMPs, CuMPs/CuNPs, $\mathrm{CuMPs} / \mathrm{CuNPs} / \mathrm{CuONPs}$ and CuMPs/CuNPs $/ \mathrm{Cu}_{2} \mathrm{ONPs}$}

Figure 3 shows the scanning electron micrographs (SEM) and the energy dispersive spectrograms (EDS) of CuMPs, CuMPs/CuNPs, CuMPs/CuNPs/CuONPs and $\mathrm{CuMPs} / \mathrm{CuNPs} / \mathrm{Cu}_{2} \mathrm{ONPs}$. The CuMPs were formed into complete microscale crystals as shown in Fig. 3(a). From Fig. 4(a), the overall histogram reported the size of copper particles ranges from of $300-1,500 \mathrm{~nm}$ with normal distribution. The average particle size of CuMPs was 1,022 $\mathrm{nm}$. This process produced no copper oxides because the ascorbic acid acted as an antioxidant agent, preventing the oxidation reaction. The EDS in Fig. 3(a) shows that this copper particle synthesis method yielded high purity copper with zero oxidation.

For CuMPs/CuNPs, the CuMPs were formed into complete crystals and the CuNPs were formed as clusters separated from CuMPs as shown in Fig. 3(b). The overall histogram reported that the particle size ranges from 50$1,000 \mathrm{~nm}$ with double-normal distribution. The average particle sizes of CuMPs and CuNPs were 575 and $118 \mathrm{~nm}$, respectively. The result suggested that the ultrasonication process in this synthesis method caused a mechanical disturbance to the solution, which reduced the size of the CuMPs and initiated the formation of the CuNPs. From Fig. 3(b), the EDS shows that this synthesis method also yielded high purity copper with zero oxidation.

For the CuMPs/CuNPs/CuONPs, the scanning electron micrographs showed that the copper particles were formed as defected face-centered cubic and CuONPs were formed as particle clusters on the surface of CuMPs and CuNPs. The average particle sizes of CuMPs, CuNPs and CuONPs were 575, 92 and $56 \mathrm{~nm}$, respectively. The carbon peak in Fig. 3(a), (b), (c) and (d) represented the graphite substrate that the particles were attached to as the method of using SEM. By neglecting the carbon weight ratio, the copper weight ratio and the oxygen weight ratio of CuMPs/CuNPs/CuONPs were $91.8 \%$ and $8.2 \%$, respectively. In this process, the ultrasonication increased the rate of the oxidization of the suspended CuMPs and CuNPs at the CuMPs and CuNPs surfaces. Because of the high reactivity of the CuNPs, the CuONPs were formed at a rapid rate on the surface of CuMPs and CuNPs clusters.

For the CuMPs/CuNPs/ $\mathrm{Cu}_{2} \mathrm{ONPs}$, the scanning electron micrographs showed that the copper particles were formed as defected face-centered cubic and $\mathrm{Cu}_{2} \mathrm{ONPs}$ were formed as particle clusters on the surface of CuMPs/CuNPs. The average particle sizes of CuMPs, CuNPs and $\mathrm{Cu}_{2} \mathrm{ONPs}$ are 568, 81 and $50 \mathrm{~nm}$, respectively. By neglecting the carbon weight ratio, the copper weight ratio and oxygen weight ratio of $\mathrm{CuMPs} / \mathrm{CuNPs} / \mathrm{Cu}_{2} \mathrm{ONPs}$ were $87.3 \%$ and $12.7 \%$, respectively. During the hydrothermal process, more $\mathrm{CuONPs}$ are produced and transformed into $\mathrm{CuO}_{2} \mathrm{NPs}$. Some of the $\mathrm{CuNPs} / \mathrm{Cu}_{2} \mathrm{ONPs}$ cluster were observed as they were broken off from the surface of the CuMPs.

In this research, we synthesized CuMPs/CuNPs under ambient conditions $\left(25^{\circ} \mathrm{C}, 1\right.$ atm) using electrochemical and ultrasonication method. A pure copper electrode (anode) was used to supply copper ions $\left(\mathrm{Cu}^{2+}\right)$ and a pure tungsten electrode was used as a cathode. Ascorbic acid $\left(\mathrm{C}_{6} \mathrm{H}_{8} \mathrm{O}_{6}\right)$ was used as a reducing agent and gum arabic was used as a stabilizer. The chemical reaction is presented in Eq. (3)

$$
\mathrm{Cu}^{2+}+\mathrm{C}_{6} \mathrm{H}_{8} \mathrm{O}_{6} \rightarrow \mathrm{Cu}_{(\mathrm{s})}+\mathrm{C}_{6} \mathrm{H}_{6} \mathrm{O}_{6}+\mathrm{H}_{2}
$$

From Eq. (3), this chemical reaction produces CuMPs/CuNPs in the solution. Gum arabic was added to reduce the mobility of the copper ions and the electrons in the solution, hence more suspended nanoparticles were maintained. Ultrasonication was used to accelerate the rate of reaction, causing rapid formation of CuMPs/CuNPs. The remaining ascorbic acid in the solution prevented the pure form of the suspended copper particles in the solution from becoming copper oxides $\left(\mathrm{CuO}\right.$ and $\left.\mathrm{Cu}_{2} \mathrm{O}\right)$ 
[32-37]. The production of copper oxides is presented in Eq. (4) and (5).

$$
\begin{aligned}
& 2 \mathrm{Cu}_{(\mathrm{s})}+\mathrm{O}_{2} \rightarrow 2 \mathrm{CuO} \\
& 4 \mathrm{Cu}_{(\mathrm{s})}+\mathrm{O}_{2} \rightarrow 2 \mathrm{Cu}_{2} \mathrm{O}
\end{aligned}
$$

According to Eq. (4), $\mathrm{CuO}$ formed in the solution at room temperature came from the copper particles and the soluble oxygen. However, this research showed that the ultrasonication greatly increased the oxidation reaction by inducing mechanical vibration, causing a large amount of CuONPs to form at the surface of CuMPs and CuNPs within a relatively short period of time (1 hours 45 minutes). $\mathrm{CuMPs} / \mathrm{CuNPs} / \mathrm{CuONPs}$ contained more surface area hence they can induce more chemical reactions.

In a low oxygen environment, $\mathrm{Cu}_{2} \mathrm{O}$ tends to form instead of $\mathrm{CuO}$ as shown in Eq. (5). This study showed that by increasing the temperature of the solution, $\mathrm{Cu}_{2} \mathrm{ONPs}$ can be formed. This suggested that, in the beginning of the hydrothermal process, the heat from the process increased the oxidation reaction, thus more $\mathrm{CuO}$ was formed. However, as the temperature increased higher, the oxygen solubility of the solution decreased, causing the $\mathrm{CuO}$ in the solution to be transformed into $\mathrm{Cu}_{2} \mathrm{O}$.
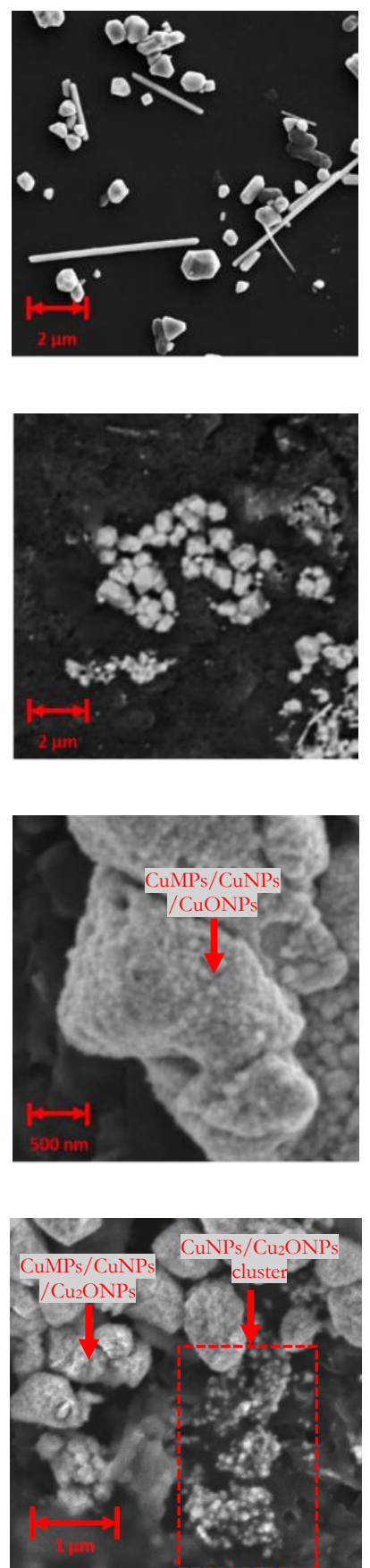

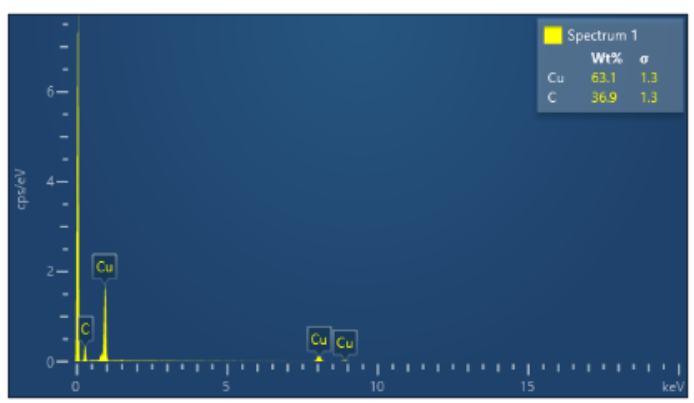

(a) CuMPs
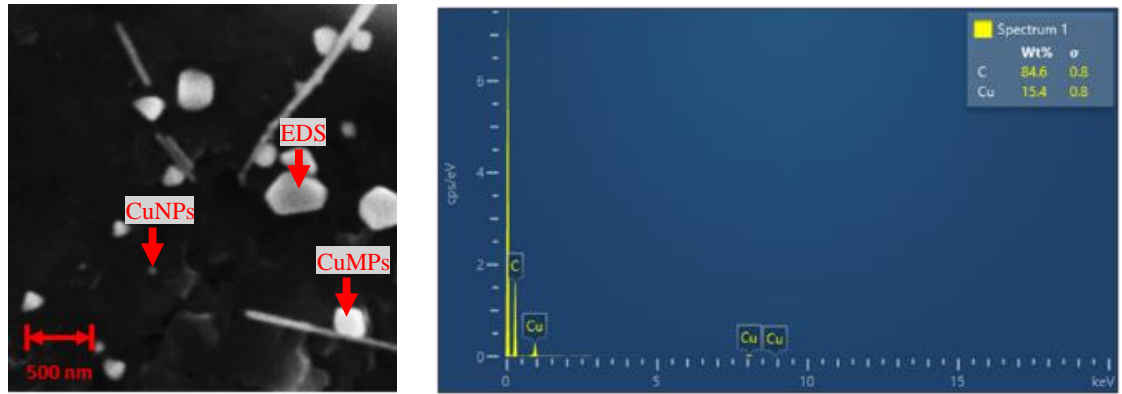

(b) CuMPs/CuNPs
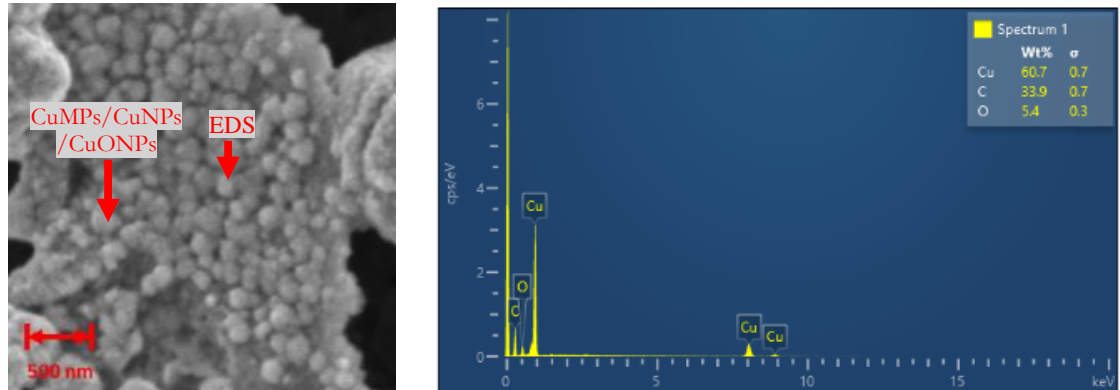

(c) $\mathrm{CuMPs} / \mathrm{CuNPs} / \mathrm{CuONPs}$
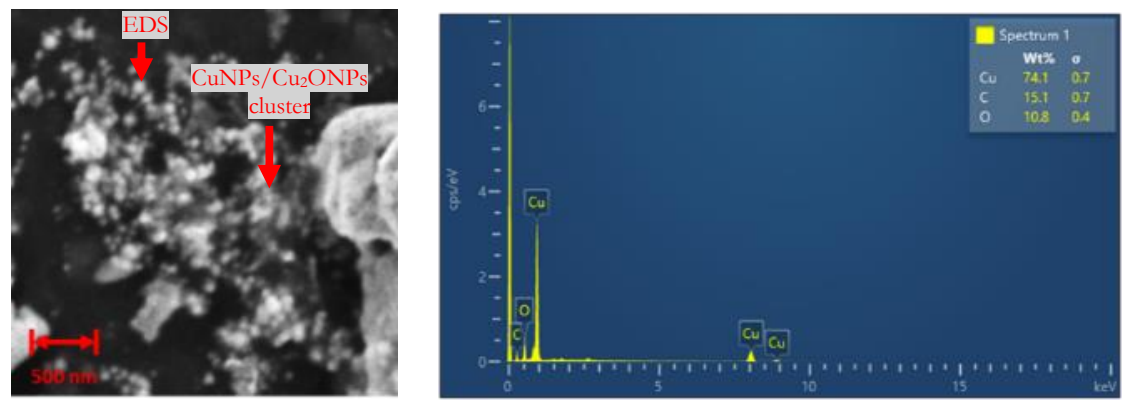

(d) $\mathrm{CuMPs} / \mathrm{CuNPs} / \mathrm{Cu}_{2} \mathrm{ONPs}$

Fig. 3. The SEM and EDS of (a) CuMPs, (b) CuMPs/CuNPs,(c) CuMPs/CuNPs/CuONPs, and (d) $\mathrm{CuMPs} / \mathrm{CuNPs} / \mathrm{Cu}_{2} \mathrm{ONPs}$. 


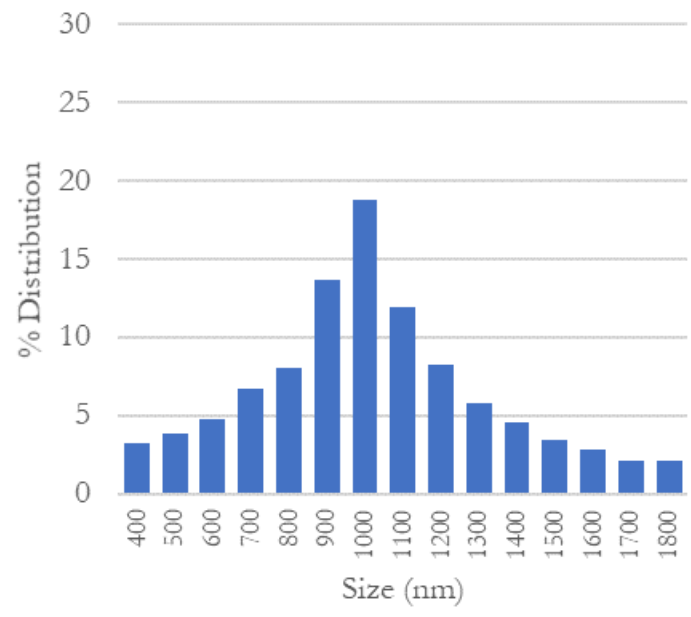

(a) CuMPs

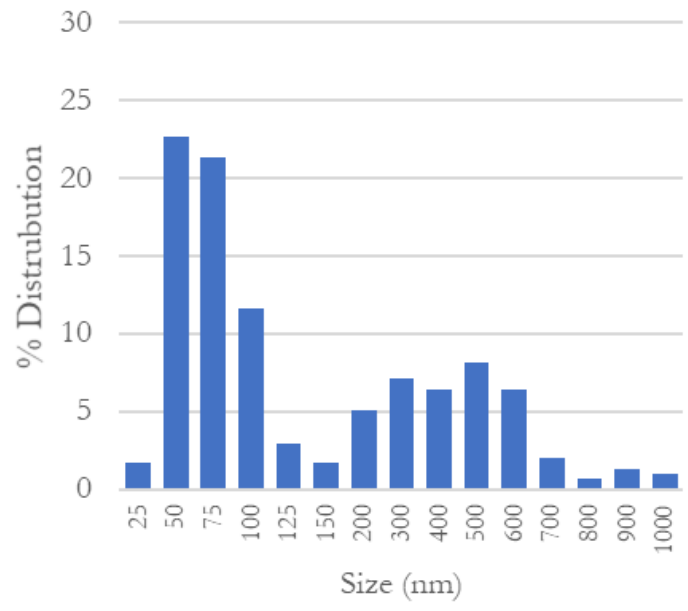

(c) CuMPs/CuNPs/CuONPs

Fig. 4. The particle size distribution of (a) CuMPs, CuMPs/CuNPs/ $\mathrm{Cu}_{2} \mathrm{ONP}$.

\subsection{Antibacterial Efficacy}

The results from the conventional bacterial identification tests are shown in Table 1.

According to Table 1, bacterial growth was found in all specimen with varying numbers. Uncountable colonies were found on all bacterial samples in DI water, CuMPs, and CuMPs/CuNPs.

In DI water, the bacterial colonies of E. coli, $S$. enteritidis, $S$. epidermidis and $S$. aureus were formed on the agar surface as the opaque biofilm. In CuMPs/CuNPs/ CuONPs, the remaining bacterial colonies of E. coli, S. enteritidis, $S$. epidermidis and $S$. aureus decreased to a moderate number. In CuMPs/CuNPs/ $\mathrm{Cu}_{2} \mathrm{ONPs}$, the remaining bacterial colonies of E. coli, $S$. enteritidis, $S$. epidermidis and $S$. aureus decreased to a smaller number than that of the CuMPs/CuNPs/CuONPs.

This study showed that the copper oxides particles tended to be more effective antibacterial agents compared to the pure form of copper particles. However, the information obtained from this study was not

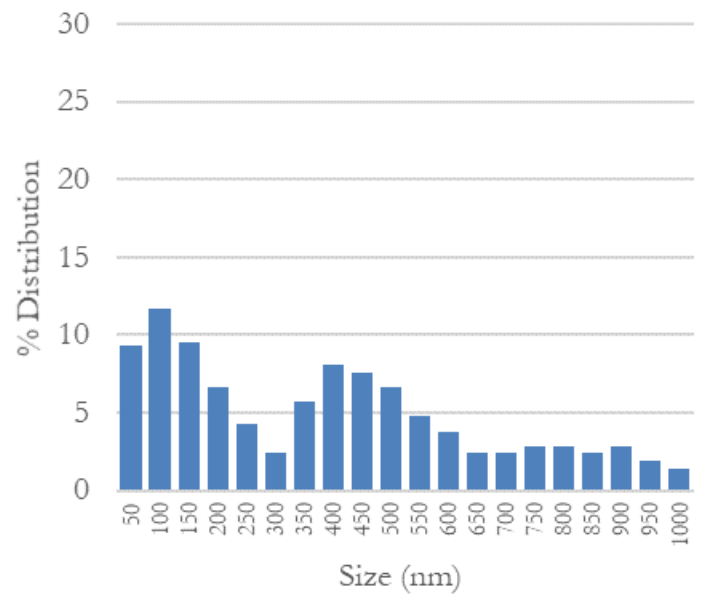

(b) $\mathrm{CuMPs} / \mathrm{CuNPs}$

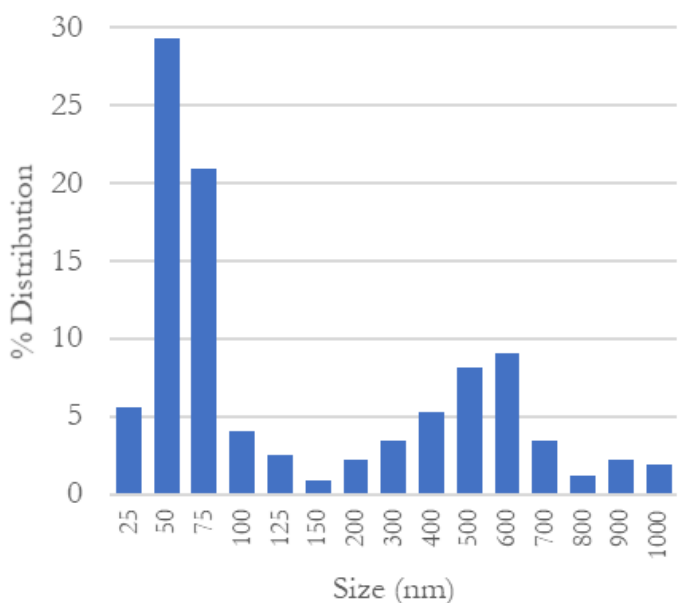

(d) $\mathrm{CuMPs} / \mathrm{CuNPs} / \mathrm{Cu}_{2} \mathrm{ONPs}$

(b) CuMPs/CuNPs, (c) CuMPs/CuNPs/CuONPs, and (d) quantitatively precise enough to indicate the effectiveness. To obtain quantitative data, conventional viable count tests were performed. The results from the conventional viable count tests are shown in Table 2.

According to Table 2, the antibacterial effect of the $0.5 \mathrm{mmol} / \mathrm{ml} \mathrm{CuMPs}$, shown as the percent reduction of bacteria (\%reduction), from the highest to the lowest were S. epidermidis $(97.33 \%), S$. enteritidis $(92.00 \%)$, E. coli $(87.78 \%)$ and $S$. aureus $(73.33 \%)$. The antibacterial effect of the $0.5 \mathrm{mmol} / \mathrm{ml} \mathrm{CuMPs} / \mathrm{CuNPs}$ from the highest to the lowest were S. epidermidis $(98.67 \%), S$. enteritidis $(96.00 \%)$, E. coli $(94.00 \%)$ and S. aureus (46.67\%). The antibacterial effect of the $0.5 \mathrm{mmol} / \mathrm{ml}$ CuMPs/CuNPs/CuONPs from the highest to the lowest were S. enteritidis (99.55\%), S. epidermidis (98.14\%), S. aureus $(96.00 \%)$ and E. coli $(94.00 \%)$. The antibacterial effect of the $0.5 \mathrm{mmol} / \mathrm{ml} \mathrm{CuMPs} / \mathrm{CuNPs} / \mathrm{Cu}_{2} \mathrm{ONPs}$ from the highest to the lowest were $S$. enteritidis $(99.99 \%), S$. epidermidis $(99.60 \%)$, E. coli $(99.40 \%)$ and S. aureus $(99.17 \%)$. The results suggested that CuMPs and CuMPs/CuNPs are very effective antibacterial agents 
against $S$. epidermidis and $S$. enteritidis, but they are less effective against E. coli and S. aureus. CuMPs/CuNPs $/ \mathrm{Cu}_{2} \mathrm{ONPs}$ are the most effective antibacterial agents in this study, since the \%reduction from all 4 bacteria are higher than $99.17 \%$

Table 1. Result from the conventional bacterial identification test.

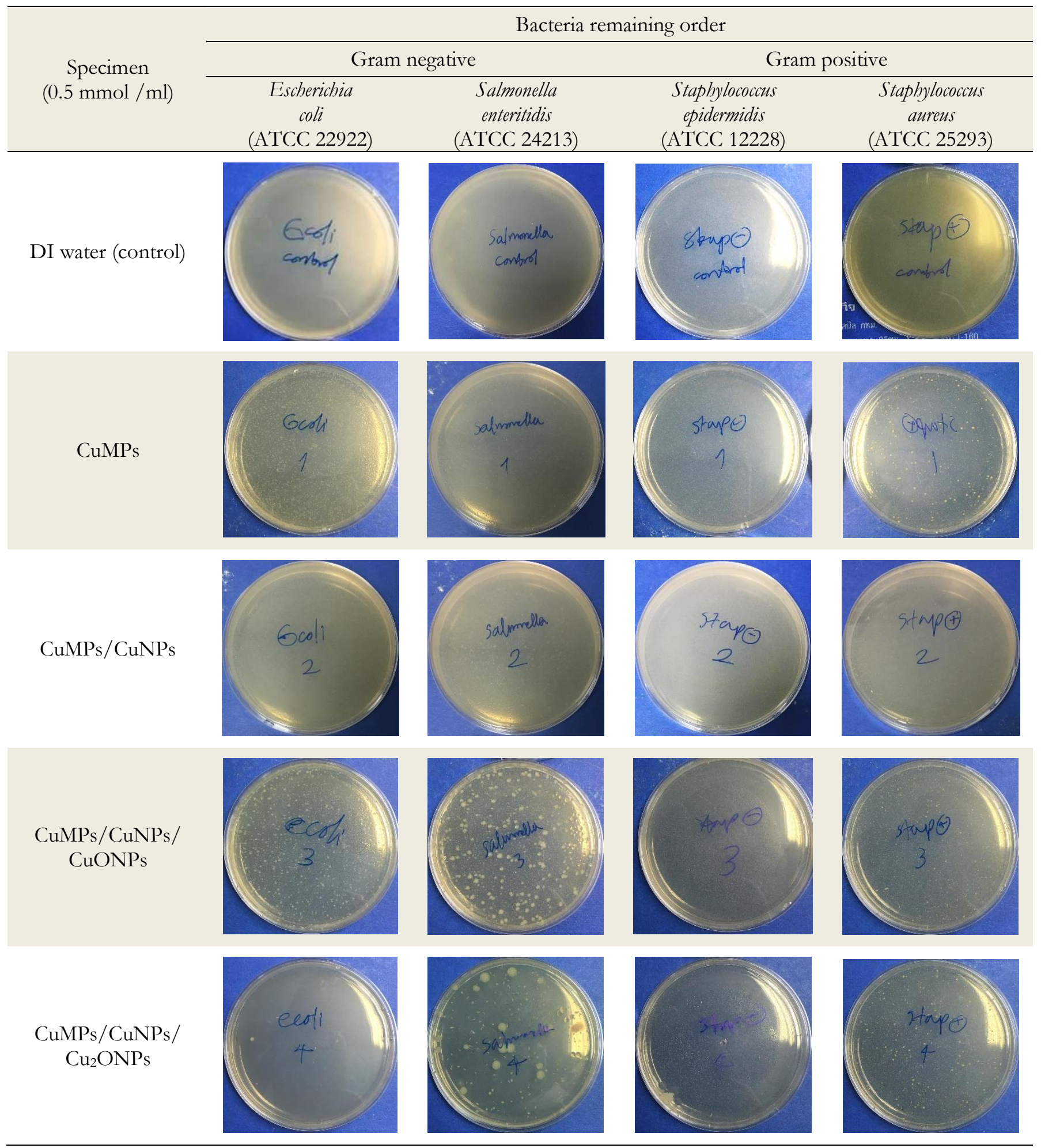


Table 2. result from the conventional viable count test.

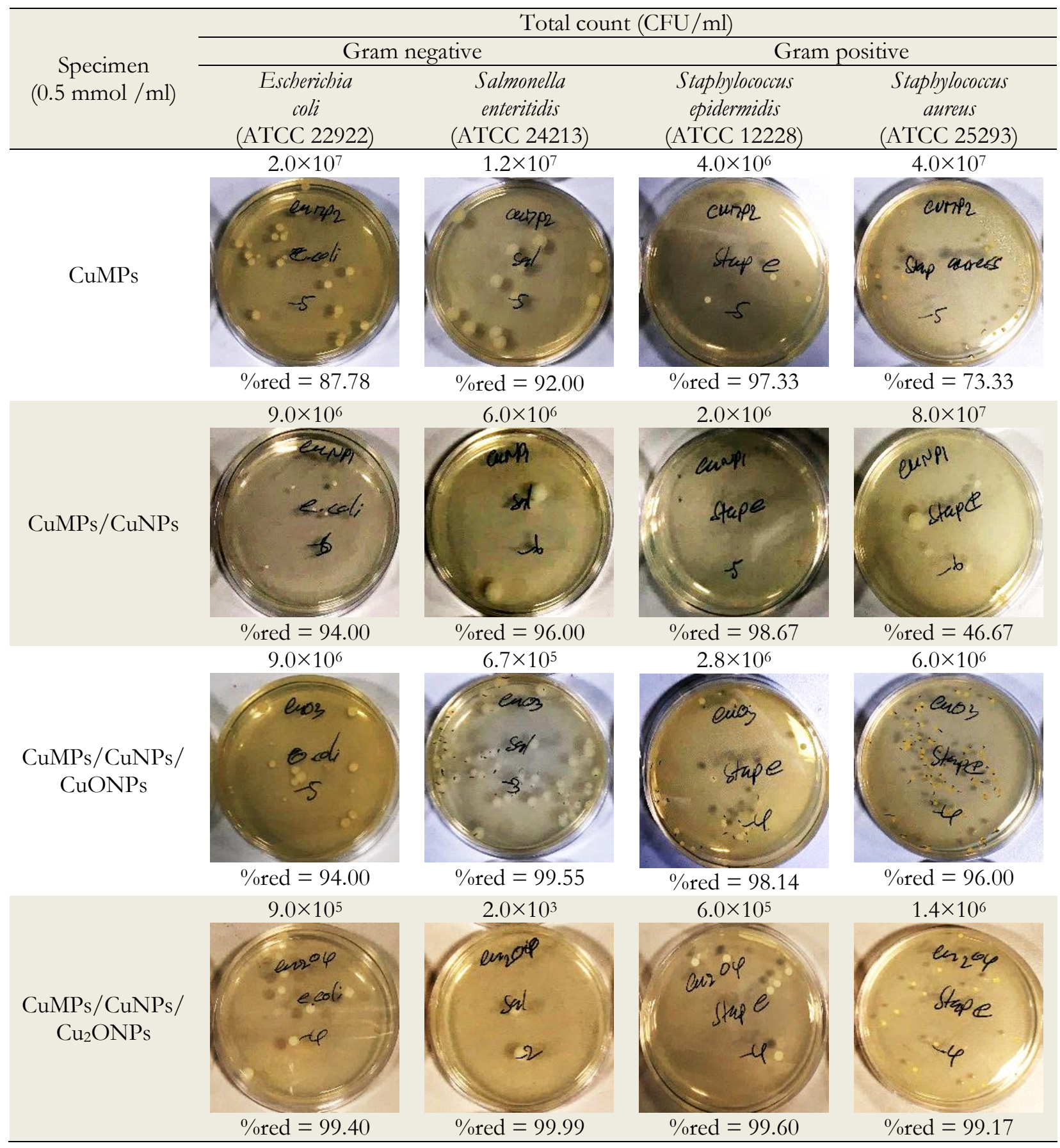

By comparing the pure form of copper, CuMPs/CuNPs exhibit higher antibacterial effects than CuMPs. The nano-sized copper formed on the surface of CuMPs provide more surface area thus enhanced the ion activities of the particles.

The bacterial identification tests and the viable count tests showed that CuMPs/CuNPs/CuONPs and $\mathrm{CuMPs} / \mathrm{CuNPs} / \mathrm{Cu}_{2} \mathrm{ONPs}$ are more effective against bacteria than CuMPs and CuMPs/CuNPs. Comparing the pure form coppers to the oxide forms, the result showed that both oxide forms are more effective against all 4 species of bacteria. This could be caused by the different ability to release the copper ions from the different oxidation-states of copper. In order for the pure form coppers to release ions, they need to be oxidized first. Furthermore, the average sizes of both oxide forms in our study are much smaller than the pure form coppers as shown in Fig. 3 and Fig. 4.

According to Fig. 3(c), the CuONPs was formed on the surface of CuMPs/CuNPs, which increased the surface area of the particles. The increased surface area of the particles enhanced their antibacterial effects by increasing of redox chemical activity and increased their ability to released copper ions. The proper concentration level of copper ions and the susceptibility of the bacteria to the ions can cause the cell membrane degradation and allow more dissolved copper ions to enter the cell. In this study, all bacteria we used are aerobic bacteria. The 
increase amount of $\mathrm{Cu}^{2+}$ and $\mathrm{CuO}$ that enter the cell, in aerobic conditions, produces high concentration of ROS. This results in higher oxidative stress causing an increase in the number of dead cells $[10,13,14,38]$.

Several study suggests that the $\mathrm{Cu}_{2} \mathrm{ONPs}$ and the CuONPs can release $\mathrm{Cu}^{+}$and $\mathrm{Cu}^{2+}$ [14]. The $\mathrm{Cu}^{2+}$ significantly increased oxidative stress by producing more ROS and the $\mathrm{Cu}^{+}$can bind to the intracellular proteins much better than $\mathrm{Cu}^{2+}$ do. This study shows that, the aerobic bacteria are highly vulnerable to CuONPs and $\mathrm{Cu}_{2} \mathrm{ONPs}$ because of the high level of the released copper ions and the high level of ROS in the bacterial cells. As such, we speculated that copper oxide particles are more effective as bactericide compare to pure copper particles.

In this study, CuMPs/CuNPs/ $\mathrm{Cu}_{2} \mathrm{ONPs}$ were shown to be more effective antibacterial agent than CuMPs/CuNPs/CuONPs against all 4 bacteria species. According to Fig. 3(d), the CuNPs $/ \mathrm{Cu}_{2} \mathrm{ONPs}$ that detached from CuMPs/CuNPs/ $\mathrm{Cu}_{2} \mathrm{ONPs}$ cluster increased the contact surface area and cuprous ionization. Cuprous ions are unstable, highly diffusible, and capable of penetrating through the bacterial cell membrane. Some studies suggested that cuprous ions deactivate bacterial cell membrane by denaturing cell membrane protein, and by destabilizing the environment $[6,13,14]$.

In our experiment, The CuONPs were transformed into $\mathrm{Cu}_{2} \mathrm{ONPs}$ on surface CuMPs/CuNPs, the process for synthesizing $\mathrm{Cu}_{2} \mathrm{ONPs}$ is an additional process to the synthesis of CuONPs. The oxidizing period for the synthesis of CuMPs/CuNPs/ $\mathrm{Cu}_{2} \mathrm{ONPs}$ was longer than the synthesis of CuMPs/CuNPs/CuONPs therefore the proportion of oxygen in $\mathrm{Cu}_{2} \mathrm{ONPs}$ was much higher than that of CuONPs.

Some study suggests that the different antibacterial effects against gram positive and gram negative bacteria were speculated as they have different cell structures and ion transport mechanisms. In order to survive, the bacteria must be able to adapt to defend themselves using the innate immune system mechanisms. Some bacteria could adapt the copper resistance by the control of homeostasis. There are three copper resistance mechanisms: (i) sending copper outside of the cell using copper-ATPase pumps and resistance-nodulation-cell division (RND) pumps (ii) reducing the effects of copper in the cell using copperbinding metal chaperone (iii) transforming more toxic form of copper $\left(\mathrm{Cu}^{+}\right)$into less toxic form $\left(\mathrm{Cu}^{2+}\right)$ by oxidation. The copper-ATPase pumps and copper-binding metal chaperone are found in both gram positive and gram negative. The RND mechanism primarily found in gram negative bacteria but less common in gram positive bacteria. The reducing copper toxicity mechanisms are found only in gram positive bacteria $[10,14]$.

Antibacterial mechanisms of both copper oxides and pure copper (CuMPs and CuMPs/CuNPs) are similar as they consist of membrane degradation and toxicity of copper from the copper ions $(\mathrm{Cu}(\mathrm{I})$ ions and $\mathrm{Cu}(\mathrm{II})$ ions). Copper oxides can readily release copper ions in negatively charged environment (e.g., bacterial proteins) but pure copper need to be oxidized first in order to released copper ions. This oxidation process required either oxidizing agents or energy, thus pure copper may require longer time to provide antibacterial effects compare to copper oxides.

The antibacterial tests we used were performed within $24 \mathrm{hrs}$. During this period of time, the pure coppers may release less copper ions than the copper oxides do. Therefore, in this study, the pure coppers appeared to be less effective in killing bacteria than the copper oxides.

Different species of bacteria may use different copperuptake mechanisms, contain different biomolecules and have different copper resistance mechanisms. Thus, they respond differently to copper and its compounds which in turn reflect on the differences in the effectiveness of the antibacterial agents.

In this study, $\mathrm{CuONPs}$ and $\mathrm{Cu}_{2} \mathrm{ONPs}$ were shown to be highly effective against both gram negative and gram positive bacteria. However, our test results show no difference in the effectiveness against gram negative and gram positive specimens. To date, there is no conclusive reports on the copper resistance of each bacterial group, and the exact effect of $\mathrm{Cu}^{+}$and $\mathrm{Cu}^{2+}$ on cell proteins and intracellular genetic materials. In our study, there is no difference between gram positive and gram negative bacteria in their resistance to copper. This suggests that copper in its nano enhanced form is more effective antibacterial agent because of its size, shape, and its oxidation state. The CuMPs/CuNPs/ $\mathrm{Cu}_{2} \mathrm{ONPs}$ are shown to be more effective than CuMPs/CuNPs $/ \mathrm{CuONPs}$, which suggested that the smaller size and the higher chemical activity of the $\mathrm{Cu}_{2} \mathrm{ONPs}$ may play a very important role in increasing the antibacterial potency of the material.

\section{Conclusions}

Ultrasono-electrochemical with hydrothermal assisted method is a green and effective method for the production of nano enhanced copper and copper oxides particles for antibacterial applications since this method neither requires nor produces toxic substances and can be performed within a relatively short period of time (less than 6 hours). Comparing CuMPs, CuMPs/CuNPs, CuMPs/CuNPs/CuONPs and CuMPs/CuNPs/ $\mathrm{Cu}_{2} \mathrm{ONPs}$, the $\mathrm{CuMPs} / \mathrm{CuNPs} / \mathrm{Cu}_{2} \mathrm{ONPs}$ are the most effective antibacterial agent in this research. Copper oxides exhibit immediate antibacterial effect since they can readily release copper ions. However, pure form coppers may provide delay antibacterial effects because they need to be oxidized first in order to release ions. Further studies about their effects on other species of microbes such as virus and fungi for the development of a broad-spectrum disinfectant, and other applications of these materials, such as electrodeposition of $\mathrm{CuONPs}$ and $\mathrm{Cu}_{2} \mathrm{ONPs}$ on a surface of a conductor, are suggested. 


\section{Acknowledgement}

The authors would like to thank Ms. Sujin Chuprasert from the Department of Oral Biology Research Center, Faculty of Dentistry, Chulalongkorn University, for providing equipment and assistance. We are grateful to Mr. Pongthai Boonkam from the Faculty of Veterinary Science, Chulalongkorn University, for providing conventional total viable count. We also would like to thank Mr. Thavorn Suwannakij from the Department of Electrical Engineering, Faculty of Engineering, Chulalongkorn University, for valuable advice and machineries. This research is financially funded by the Chulalongkorn University Graduate School Thesis Grant.

\section{Reference}

[1] R. Varshney, S. Bhadauria, and M. S. Gaur, "A review: biological synthesis of silver and copper nanoparticles," Nano Biomedicine \& Engineering, vol. 4, no. 2, 2012.

[2] S. Xiao, P. Liu, W. Zhu, G. Li, D. Zhang, and H. Li, "Copper nanowires: a substitute for noble metals to enhance photocatalytic $\mathrm{H}_{2}$ generation," Nano Letters, vol. 15, no. 8, pp. 4853-4858, 2015.

[3] S.-J. Joo, H.-J. Hwang, and H.-S. Kim, "Highly conductive copper nano/microparticles ink via flash light sintering for printed electronics," Nanotechnology, vol. 25, no. 26, pp. 265601, 2014.

[4] T. Oishi, K. Koyama, M. Tanaka, and J.-C. Lee, "Influence of electrolyte on an energy-saving copper recycling process using ammoniacal alkaline solutions," Materials Transactions, vol. 47, no. 11, pp. 2871-2876, 2006.

[5] A. Hafeez, A. Razzaq, T. Mahmood, and H. M. Jhanzab, "Potential of copper nanoparticles to increase growth and yield of wheat," J Nanosci $A d v$ Technol, vol. 1, no. 1, pp. 6-11, 2015.

[6] B. K. Meyer et al., "The physics of copper oxide $\left(\mathrm{Cu}_{2} \mathrm{O}\right)$, , Semiconductors and Semimetals, vol. 88, pp. 201-226, 2013.

[7] N. D. Nikolić, K. I. Popov, L. J. Pavlović, and M. G. Pavlović, "The effect of hydrogen codeposition on the morphology of copper electrodeposits. I. The concept of effective overpotential," Journal of Electroanalytical Chemistry, vol. 588, no. 1, pp. 88-98, 2006.

[8] D. Mott, J. Galkowski, L. Wang, J. Luo, and C.-J. Zhong, "Synthesis of size-controlled and shaped copper nanoparticles," Langmuir, vol. 23, no. 10, pp. 5740-5745, 2007.

[9] R. Wang and H. Ruan, "Synthesis of copper nanowires and its application to flexible transparent electrode," Journal of Alloys and Compounds, vol. 656, pp. 936-943, 2016.

[10] S. Meghana, P. Kabra, S. Chakraborty, and N. Padmavathy, "Understanding the pathway of antibacterial activity of copper oxide nanoparticles," RSC advances, vol. 5, no. 16, pp. 12293-12299, 2015.
[11] K. L. Sundberg, "Application of materials characterization, efficacy testing, and modelling methods on copper cold spray coatings for optimized antimicrobial properties," doctoral dissertation, Worchester Polytechnic Institute, 2019.

[12] C. Angelé-Martínez, K. V. T. Nguyen, F. S. Ameer, J. N. Anker, and J. L. Brumaghim, "Reactive oxygen species generation by copper (II) oxide nanoparticles determined by DNA damage assays and EPR spectroscopy," Nanotoxicology, vol. 11, no. 2, pp. 278288, 2017.

[13] M. Hans, A. Erbe, S. Mathews, Y. Chen, M. Solioz, and F. Mücklich, "Role of copper oxides in contact killing of bacteria," Langmuir, vol. 29, no. 52, pp. 16160-16166, 2013.

[14] M. Vincent, R. E. Duval, P. Hartemann, and M. Engels-Deutsch, "Contact killing and antimicrobial properties of copper," Journal of Applied Microbiology, vol. 124, no. 5, pp. 1032-1046, 2018.

[15] M. I. Irshad, F. Ahmad, N. M. Mohamed, and M. Z. Abdullah, "Preparation and structural characterization of template assisted electrodeposited copper nanowires," Int. J. Electrochem. Sci, vol. 9, no. 5, pp. 2548-2555, 2014.

[16] N. M. Zain, A. G. F. Stapley, and G. Shama, "Green synthesis of silver and copper nanoparticles using ascorbic acid and chitosan for antimicrobial applications," Carbohydrate Polymers, vol. 112, pp. 195202, 2014.

[17] S. Yallappa, J. Manjanna, M. A. Sindhe, N. D. Satyanarayan, S. N. Pramod, and K. Nagaraja, "Microwave assisted rapid synthesis and biological evaluation of stable copper nanoparticles using $\mathrm{T}$. arjuna bark extract," Spectrocbimica Acta Part A: Molecular and Biomolecular Spectroscopy, vol. 110, pp. 108-115, 2013.

[18] M. Tanghatari, Z. N. Sarband, S. Rezaee, and K. Larijani, "Microwave assisted green synthesis of copper nanoparticles," Bulgarian Chemical Communications, pp. 347-352, 2017.

[19] Q.-m. Liu, D.-b. Zhou, Y. Yamamoto, R. Ichino, and M. Okido, "Preparation of $\mathrm{Cu}$ nanoparticles with $\mathrm{NaBH} 4$ by aqueous reduction method," Transactions of Nonferrous Metals Society of China, vol. 22, no. 1, pp. 117-123, 2012.

[20] J. Xiong, Y. Wang, Q. Xue, and X. Wu, "Synthesis of highly stable dispersions of nanosized copper particles using L-ascorbic acid," Green Chemistry, vol. 13, no. 4, pp. 900-904, 2011.

[21] C. Sun, Y. Li, Z. Li, Q. Su, Y. Wang, and X. Liu, "Durable and washable antibacterial copper nanoparticles bridged by surface grafting polymer brushes on cotton and polymeric materials," Journal of Nanomaterials, vol. 2018, 2018.

[22] Y. S. Lee, B. Bora, S. L. Yap, and C. S. Wong, "Effect of ambient air pressure on synthesis of copper and copper oxide nanoparticles by wire explosion process," Current Applied Physics, vol. 12, no. 1, pp. 199-203, 2012. 
[23] P. Wankhede, P. K. Sharma, and A. K. Jha, "Synthesis of copper nanoparticles through wire explosion route," J. Eng. Res. and Appl, vol. 3, no. 6, pp. 1664-1669, 2013.

[24] A. V. Simakin, V. V. Voronov, and G. A. Shafeev, "Nanoparticle formation during laser ablation of solids in liquids," Physics of Wave Phenomena, vol. 15, no. 4, pp. 218-240, 2007.

[25] Y. Shimotsuma et al., "Photoconversion of copper flakes to nanowires with ultrashort pulse laser irradiation," Chemistry of materials, vol. 19, no. 6, pp. 1206-1208, 2007.

[26] R. M. Tilaki and S. M. Mahdavi, "Size, composition and optical properties of copper nanoparticles prepared by laser ablation in liquids," Applied Physics A, vol. 88, no. 2, pp. 415-419, 2007.

[27] G. Xiao, P. Gao, L. Wang, Y. Chen, Y. Wang, and G. Zhang, "Ultrasonochemical-assisted synthesis of $\mathrm{CuO}$ nanorods with high hydrogen storage ability," Journal of Nanomaterials, vol. 2011, 2011.

[28] K. Y. Hwa, P. Karuppaiah, N. S. K. Gowthaman, V. Balakumar, S. Shankar, and H. N. Lim, "Ultrasonic synthesis of $\mathrm{CuO}$ nanoflakes: A robust electrochemical scaffold for the sensitive detection of phenolic hazard in water and pharmaceutical samples," Ultrasonics sonochemistry, vol. 58, pp. 104649, 2019.

[29] H. Yu, J. Yu, S. Liu, and S. Mann, "Template-free hydrothermal synthesis of $\mathrm{CuO} / \mathrm{Cu}_{2} \mathrm{O}$ composite hollow microspheres," Chemistry of materials, vol. 19, no. 17, pp. 4327-4334, 2007.

[30] R. Ji, W. Sun, and Y. Chu, "One-step hydrothermal synthesis of a porous $\mathrm{Cu}_{2} \mathrm{O}$ film and its photoelectrochemical properties," ChemPhysChem, vol. 14, no. 17, pp. 3971-3976, 2013.
[31] F. Diez-Gonzalez, "Total viable counts|Specific techniques," in Encyclopedia of Food Microbiology, 2nd ed. 2014.

[32] A. Umer, S. Naveed, N. Ramzan, and M. S. Rafique, "Selection of a suitable method for the synthesis of copper nanoparticles," Nano, vol. 7, no. 05, p. 1230005, 2012.

[33] J. Xiong, X.-d. Wu, and Q.-j. Xue, "Biomoleculeassisted synthesis of highly stable dispersions of water-soluble copper nanoparticles," Journal of colloid and interface science, vol. 390, no. 1, pp. 41-46, 2013.

[34] M. Biçer and İ. Şişman, "Controlled synthesis of copper nano/microstructures using ascorbic acid in aqueous CTAB solution," Powder Technology, vol. 198, no. 2, pp. 279-284, 2010.

[35] T. M. D. Dang, T. T. T. Le, E. Fribourg-Blanc, and M. C. Dang, "Synthesis and optical properties of copper nanoparticles prepared by a chemical reduction method," Advances in Natural Sciences: Nanoscience and Nanotechnology, vol. 2, no. 1, p. 015009 , 2011.

[36] S. S. Sawant, A. D. Bhagwat, and C. M. Mahajan, "Novel facile technique for synthesis of stable cuprous oxide $\left(\mathrm{Cu}_{2} \mathrm{O}\right)$ nanoparticles-An ageing effect," Journal of Nano- and Electronic Physics, vol. 8, no. 1, p. 01036, 2016.

[37] M. J. Nine, B. Munkhbayar, M. S. Rahman, H. Chung, and $\mathrm{H}$. Jeong, "Highly productive synthesis process of well dispersed $\mathrm{Cu}_{2} \mathrm{O}$ and $\mathrm{Cu} / \mathrm{Cu}_{2} \mathrm{O}$ nanoparticles and its thermal characterization," Materials Chemistry and Physics, vol. 141, no. 2-3, pp. 636-642, 2013.

[38] S. Mathews, R. Kumar, and M. Solioz, "Copper reduction and contact killing of bacteria by iron surfaces," Applied and environmental microbiology, vol. 81, no. 18, pp. 6399-6403, 2015. 


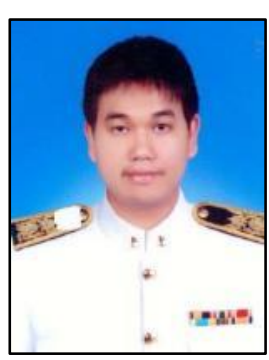

Pachara Chalayon was born in Ubon Ratchathani, Thailand in 1986. He obtained the Bachelor of Engineering degree in electrical engineering from the Kasetsart University, Thailand in 2009 and the Master of Engineering degree in electrical engineering from the Chulalongkorn University, Thailand in 2013. Since 2014, he has served as a control and instrument engineer in the Electricity Generating Authority of Thailand. From 2016 to present, he currently pursuing his Doctor of Engineering degree in Chulalongkorn University, Thailand. His research interests are energy management system, nanotechnology, semiconductor and biomedical electronics.

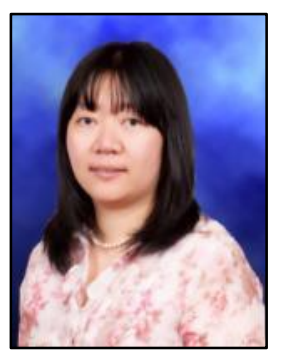

Chanchana Tangwongsan was born in Bangkok, Thailand in 1974. She obtained the Bachelor of Engithaneering degree in electrical engineering from Chulalongkorn University, Bangkok, Thailand in 1996, MS degree and the Ph.D. in biomedical Engineering from Uinversity of Wiscone-Madison, WI, USA in 1999 and in 2003, respectively.

From 2003, she has been a faculty member in the Department of Electrical Engineering, Faculty of Engineering, Chulalongkorn University. 